\title{
Connexin43 recruits PTEN and Csk to inhibit c-Src activity in glioma cells and astrocytes
}

\author{
Ana González-Sánchez ${ }^{1}$, Myriam Jaraíz-Rodríguez ${ }^{1}$, Marta Domínguez-Prieto ${ }^{1}$, \\ Sandra Herrero-González ${ }^{1}$, José M. Medina ${ }^{1}$, Arantxa Tabernero ${ }^{1}$ \\ ${ }^{1}$ Instituto de Neurociencias de Castilla y León (INCYL), Departamento de Bioquímica y Biología Molecular, Universidad de \\ Salamanca, Salamanca, Spain
}

Correspondence to: Arantxa Tabernero, email: ataber@usal.es

Keywords: connexin, Src, glia, CNS, gap junctions

Received: December 10, $2015 \quad$ Accepted: June 26, 2016

Published: July 06, 2016

\section{ABSTRACT}

Connexin43 (Cx43), the major protein forming gap junctions in astrocytes, is reduced in high-grade gliomas, where its ectopic expression exerts important effects, including the inhibition of the proto-oncogene tyrosine-protein kinase Src (c-Src). In this work we aimed to investigate the mechanism responsible for this effect. The inhibition of c-Src requires phosphorylation at tyrosine 527 mediated by C-terminal Src kinase (Csk) and dephosphorylation at tyrosine $\mathbf{4 1 6}$ mediated by phosphatases, such as phosphatase and tensin homolog (PTEN). Our results showed that the antiproliferative effect of Cx43 is reduced when Csk and PTEN are silenced in glioma cells, suggesting the involvement of both enzymes. Confocal microscopy and immunoprecipitation assays confirmed that $\mathrm{Cx} 43$, in addition to c-Src, binds to PTEN and Csk in glioma cells transfected with Cx43 and in astrocytes. Pull-down assays showed that region $266-283$ in $\mathrm{Cx} 43$ is sufficient to recruit c-Src, PTEN and Csk and to inhibit the oncogenic activity of c-Src. As a result of c-Src inhibition, PTEN was increased with subsequent inactivation of Akt and reduction of proliferation of human glioblastoma stem cells. We conclude that the recruitment of Csk and PTEN to the region between residues 266 and 283 within the C-terminus of Cx43 leads to c-Src inhibition.

\section{INTRODUCTION}

Connexin43 $(\mathrm{Cx} 43)$ is an integral membrane protein that assembles to form gap junction channels and hemichannels in different cell types, including astrocytes, where $\mathrm{Cx} 43$ is strongly expressed $[1,2]$. However, the levels of $\mathrm{Cx} 43$ protein are decreased when these cells acquire a malignant phenotype. In fact, the levels of $\mathrm{Cx} 43$ protein are inversely correlated with the degree of malignancy in astrocytomas, being negligible in the majority of glioblastomas, the most common glioma that unfortunately carries the worst prognosis [3-9]. Even in glioma-initiating cells or glioblastoma stem cells (GSCs)-a subpopulation of cells within malignant gliomas that are characterized by their self-renewal capacity, multilineage differentiation properties, high oncogenic potential, and resistance to standard therapies [10]- the levels of $\mathrm{Cx} 43$ are negligible $[11,12]$.
The proto-oncogene tyrosine-protein kinase $\mathrm{Src}$ (c-Src) participates in signaling pathways that control a diverse spectrum of biological events, including proliferation, differentiation, survival and migration [13]. c-Src binds to Cx43 through the Src homology 3 (SH3) domain binding motif of $\mathrm{Cx} 43$, a proline-rich region (amino acids 274-283), and then phosphorylates tyrosine 265, providing an SH2 domain binding site with subsequent phosphorylation at tyrosine 247 [14]. As a consequence of these phosphorylations, gap junctional intercellular communication is reduced [15-17], and Cx43 turnover is initiated [18]. More recently, it has been found that in addition to these effects, the interaction of Cx43 with c-Src can reciprocally inhibit c-Src activity $[11,19]$. Glioblastoma cells exhibit strong c-Src activity [20], which plays an important role in the transforming phenotype of astrocytomas [21]. Autophosphorylation at tyrosine 416 activates c-Src, contributing to the malignant 
phenotype [22]. Interestingly, restoring $\mathrm{Cx} 43$ to glioma cells reduces c-Src activity by decreasing the active form of c-Src (c-Src phosphorylated at tyrosine 416; Y416 $\mathrm{c}-\mathrm{Src})$ and increasing the inactive form of $\mathrm{c}-\mathrm{Src}$ (c-Src phosphorylated at tyrosine 527; Y527 c-Src) [19]. The inhibition of c-Src is not promoted by mutant $\mathrm{Cx} 43$, which lacks the ability to bind to c-Src [19]. Rather, it is promoted by cell-penetrating peptides containing the region of $\mathrm{Cx} 43$ involved in c-Src interaction [11]. Collectively, these data indicate that the interaction of $\mathrm{Cx} 43$ with c-Src reduces c-Src activity; therefore, these proteins are mutually regulated by a phosphorylation/ dephosphorylation loop. c-Src activity is linked to crucial signaling pathways [23]. Consequently, it is not surprising that the inhibition of $\mathrm{c}-\mathrm{Src}$ promoted by $\mathrm{Cx} 43$ reduces the cell cycle $[11,19]$, glucose uptake $[24,25]$ or glioma stem cell phenotype [11, 19] (for a review, see [26]).

Despite the relevance of c-Src inhibition for cell biology, the mechanism by which the interaction of $\mathrm{Cx} 43$ with c-Src reduces its activity is unknown. The inhibition of c-Src requires the activity of the C-terminal c-Src kinase (Csk), which phosphorylates c-Src at tyrosine 527 [27]. In addition, several phosphatases, such as phosphatase and tensin homolog (PTEN), have been shown to dephosphorylate c-Src at tyrosine 416 [28], an activity that is required to complete the inactivation of c-Src. In this study, we found that a small region located in the C-terminal domain of $\mathrm{Cx} 43$ serves as a docking platform for c-Src, PTEN and Csk, favoring the inhibition of the oncogenic activity of c-Src.

\section{RESULTS}

\section{Csk and PTEN are involved in the inhibition of glioma cell growth promoted by $\mathrm{Cx} 43$}

In previous studies, we showed that restoring $\mathrm{Cx} 43$ to glioma cells inhibits c-Src activity and consequently their rate of proliferation [11, 19]. Because Csk, through phosphorylation of c-Src at tyrosine 527, is the main enzyme responsible for c-Src inhibition [27], in this study, we addressed the participation of Csk in the antiproliferative effect of $\mathrm{Cx} 43$. To do so, the expression of Csk was knocked-down by a specific siRNA (Csk-siRNA) [29] in C6 glioma cells stably transfected with Cx43 (C6$\mathrm{Cx} 43$ ) or the empty vector (C6-Ires). Figure 1A shows that Csk-siRNA strongly reduced the expression of Csk in both C6-Ires and C6-Cx43 cells at concentrations ranging from 25 to $75 \mathrm{nM}$. Next, the growth of C6-Ires and C6CX43 cells, transfected with $50 \mathrm{nM}$ non-targeting siRNA (NT-siRNA), or Csk-siRNA, was followed using the MTT assay. Figure 1B shows that, as expected, restoring $\mathrm{Cx} 43$ reduced the rate of glioma cell growth in the control situation (cells transfected with NT-siRNA). However, when Csk was silenced the effect of $\mathrm{Cx} 43$ on glioma cell proliferation was reduced, suggesting the contribution of
Csk to the antiproliferative effect of $\mathrm{Cx} 43$. It should be mentioned that the growth rate increased when Csk was silenced in both C6-Ires $(p<0.01$ at days 3 and 4, and $p<0.001$ for the other days) and C6-Cx43 ( $p<0.05$ at day 3 and $p<0.001$, for the other days) cells compared with cells transfected with NT-siRNA.

In addition to the phosphorylation at tyrosine 527 by Csk, to be completely inactivated, c-Src needs to be dephosphorylated at tyrosine 416 . Several phosphatases, including PTEN, have been shown to dephosphorylate c-Src at tyrosine 416 [28]. To investigate the participation of PTEN in the inhibition of c-Src promoted by $\mathrm{Cx} 43$ [19], the levels of Y416 c-Src were analyzed in glioma cells in which PTEN was knocked-down by siRNA [30] (Figure 1C-1E). As expected, $\mathrm{Cx} 43$ decreased the ratio of Y416 c-Src / total c-Src in glioma cells transfected with NT-siRNA (Figure 1E). By contrast, when PTEN was silenced by a specific siRNA (PTEN-siRNA), Cx43 could not reduce this ratio (Figure 1E), suggesting that PTEN is involved in the dephosphorylation of c-Src at tyrosine 416. Next, we investigated the participation of PTEN in the antiproliferative effect of $\mathrm{Cx} 43$. Our results showed that silencing PTEN reduced the antiproliferative effect of $\mathrm{Cx} 43$ on glioma cells compared with glioma cells transfected with NT-siRNA (Figure 1B). The growth rate increased when PTEN was silenced in both C6-Ires ( $p<0.01$ at days 3 and 7 , and $p<0.001$ for the other days) and C6-Cx43 $(p<0.01$ at days 3 and 7, and $p<0.001$ for the other days) cells compared with cells transfected with NT-siRNA.

\section{Restoring Cx43 expression in glioma cells increases PTEN by a c-Src-dependent mechanism}

Unexpectedly, we observed that the presence of $\mathrm{Cx} 43$ increased PTEN protein levels in glioma cells (Figure 1C). Because PTEN is one of the most relevant tumor suppressor proteins in gliomas [31], we decided to explore this effect. To this end, the levels of PTEN were analyzed in C6-Ires and C6-Cx43 cells. Our results showed that restoring $\mathrm{Cx} 43$ expression doubled the levels of PTEN protein in glioma cells (Figure 2A and 2C).

To confirm the functionality of PTEN, we analyzed its downstream pathway. PTEN exhibits both lipid and protein phosphatase activities. The main substrate for the lipid phosphatase activity is phosphatidylinositoltrisphosphate (PIP3), which is dephosphorylated by PTEN to generate PIP2. PIP3 is the main activator of Akt [32]. Thus, the higher the activity of PTEN, the lower the activity of Akt. In agreement with this concept, restoring $\mathrm{Cx} 43$ expression reduced Akt activity as shown by the concomitant reduction in the levels of Akt phosphorylated at serine 473 and threonine 308 (Figure 2A, 2G and 2H) and the increase in PTEN levels (Figure 2A and 2C). 
A

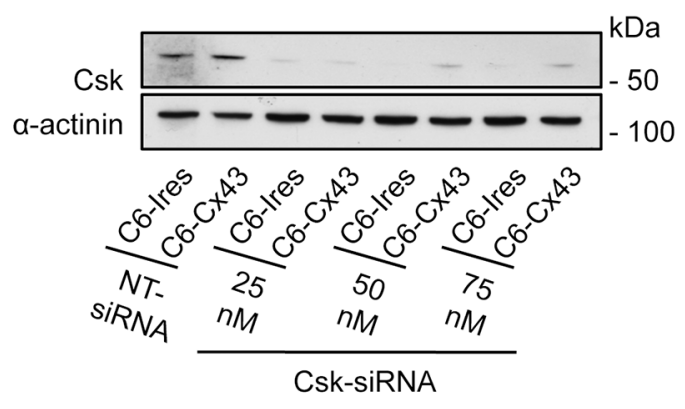

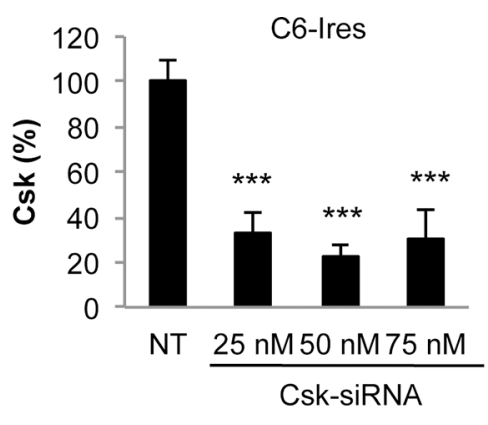

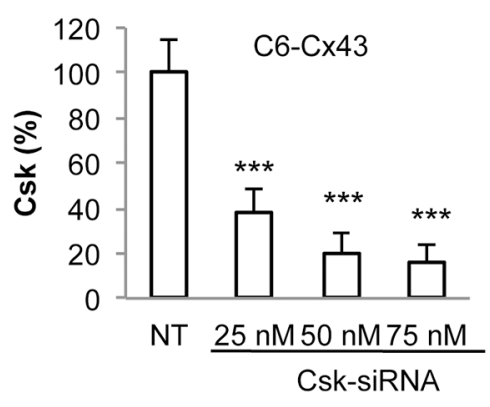

B

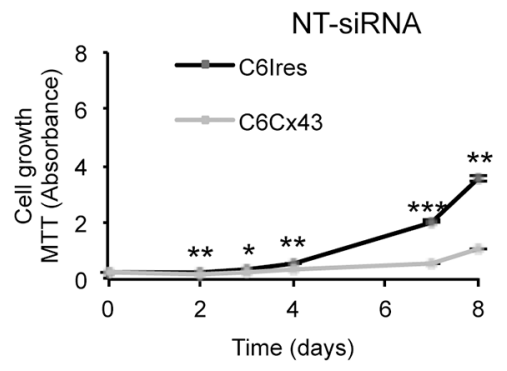

C

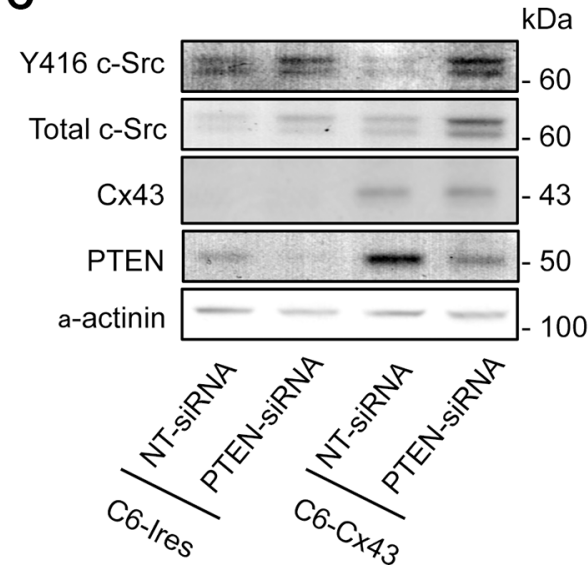

Csk-siRNA

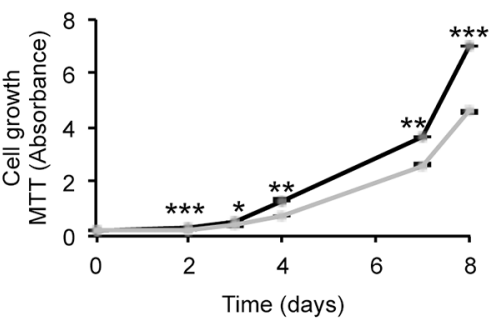

D

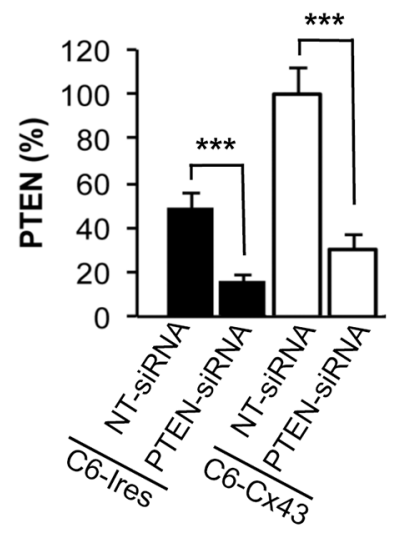

PTEN-SiRNA

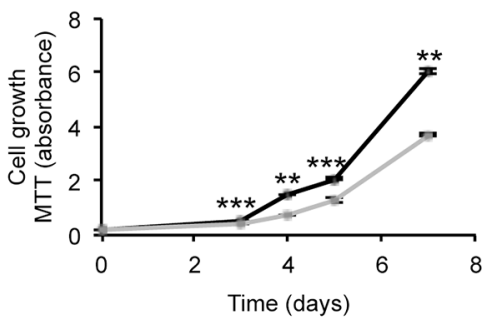

E

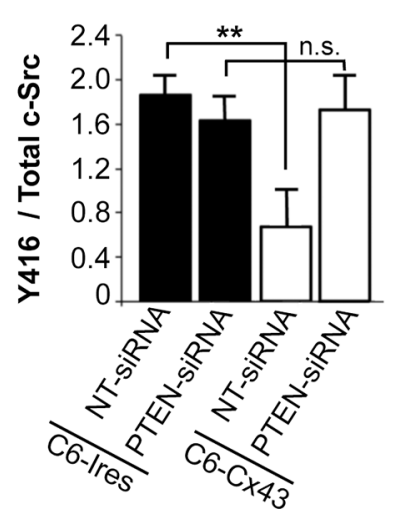

Figure 1: Effect of silencing Csk and PTEN on the reduction of proliferation promoted by Cx43. C6 cells stably transfected with the empty vector (C6-Ires) or the vector containing the Cx43 cDNA (C6-Cx43) were transfected with Csk-siRNA, PTEN-siRNA or non-targeting siRNA (NT-siRNA). (A) The levels of Csk were analyzed by Western blotting $72 \mathrm{~h}$ after transfection with increasing concentrations of Csk-siRNA or $50 \mathrm{nM}$ NT-siRNA. The results are the means \pm s.e.m. $(n=3)$ and they are expressed as the percentage of the corresponding NT-siRNA. $* * * p<0.001$ versus the corresponding NT-siRNA. (B) The cells transfected with the indicated siRNAs were plated at 2000 cells $/ \mathrm{cm}^{2}$, and the number of living cells was followed by the MTT assay. The results are the means \pm s.e.m. $(n=4)$ and they are expressed as the absorbance values of the MTT assay. ${ }^{*} p<0.05, * * p<0.01, * * * p<0.001$; C6-Ires versus C6-Cx43. (C) Cells were transfected with 50 nM NT-siRNA or PTEN-siRNA. After 48 h, PTEN, Cx43, total c-Src and Y416 c-Src levels were analyzed by Western blotting. The results are the means \pm s.e.m. $(n=6)$ and they are expressed as the percentage of the C6-Cx43 NT-siRNA (D) or as the ratio of Y416 c-Src/total c-Src (E). n.s: not significant. $* * p<0.01$ and $* * * p<0.001$. 
A
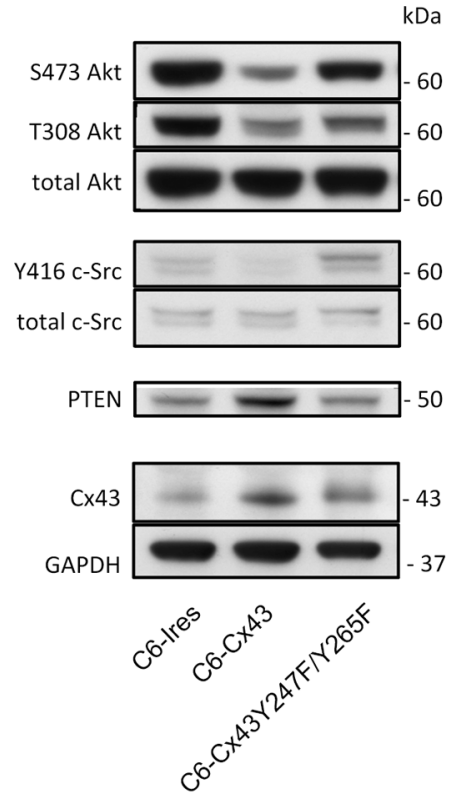

C

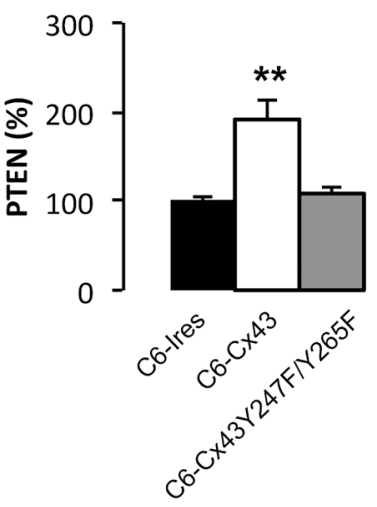

$\mathbf{F}$

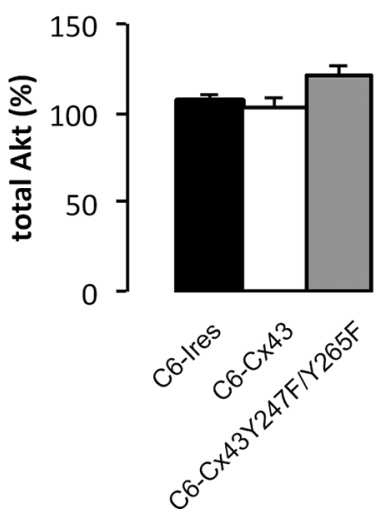

B

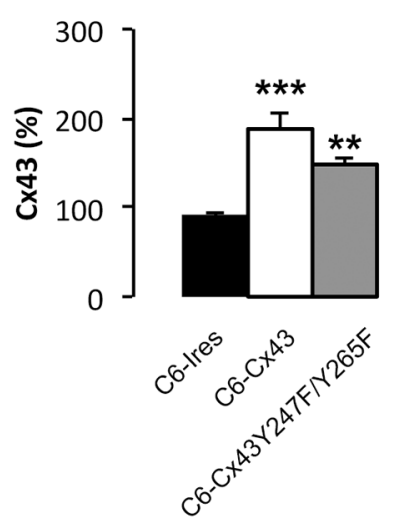

D

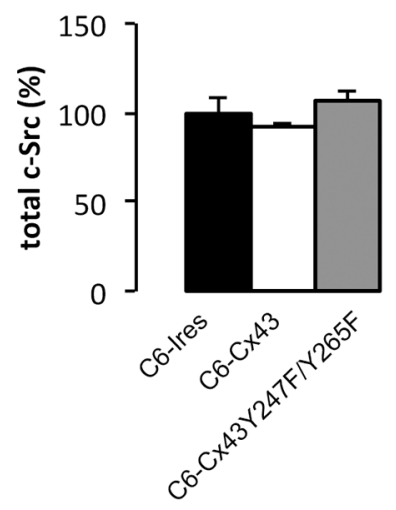

G

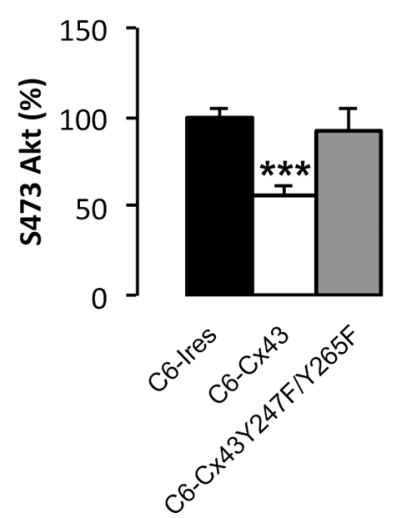

E

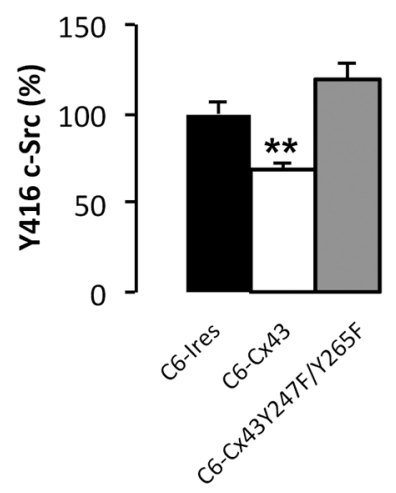

H

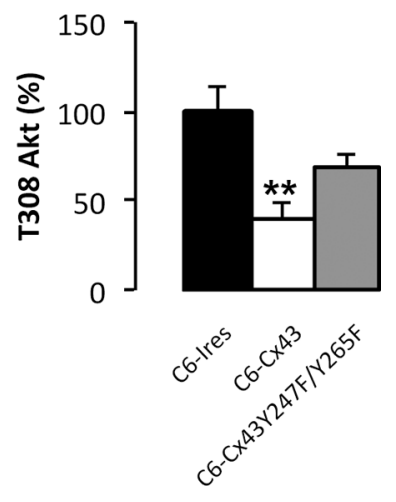

Figure 2: Effect of Cx43 and mutant Cx43 expression on PTEN expression and Akt activity. C6 glioma cells were stably transfected with the empty vector (C6-Ires), the vector containing the Cx43 cDNA (C6-Cx43), or the vector containing the cDNA encoding the double mutant $\mathrm{Cx} 43$ in which tyrosine 247 and tyrosine 265 of $\mathrm{Cx} 43$ were replaced by non-phosphorylatable phenylalanines (C6-Cx43 Y247F/Y265F). Western blots (A) and quantification of Cx43 (B), PTEN (C), total c-Src (D), Y416 c-Src (E), total Akt (F), S473 Akt (G) and T308 Akt $(\mathbf{H})$. The results are the means \pm s.e.m. $(n=6)$ and they are expressed as percentage of the value generated by C6-Ires cells. ${ }^{*} p<0.05,{ }^{* *} p<0.01,{ }^{* * *} p<0.001$ versus C6-Ires. 
Because the activity of c-Src promotes PTEN degradation and reduces its ability to inhibit the PI3K/Akt pathway [33], we analyzed the involvement of c-Src in the effect of Cx43 on PTEN. C6 cells were stably transfected with a double $\mathrm{Cx} 43$ mutant in which tyrosines 247 and 265 were replaced with non-phosphorylatable phenylalanines (C6-Cx43Y247F/Y265F). This mutant lacks the ability to bind to c-Src $[15,17]$ and, consequently, does not inhibit c-Src activity like wild-type Cx43 [19] (Figure 2A, 2D and 2E). Our results showed that the mutant $\mathrm{Cx} 43$ did not significantly modify the levels of PTEN (Figure 2A and 2C), suggesting that the $\mathrm{Cx} 43$-mediated inactivation of $\mathrm{c}-\mathrm{Src}$ is required to increase the levels of PTEN. In agreement with the lack of effect on PTEN levels, mutant Cx43 did not significantly modify the levels of active Akt phosphorylated at serine 473 and threonine 308 (Figure 2A, 2G and 2H).

\section{Cx43 binds to PTEN and Csk}

The ability of $\mathrm{Cx} 43$ to bind to c-Src has been well described [15, 17, 34]. Because our results suggested that Csk and PTEN participate in the inhibition of c-Src activity promoted by $\mathrm{Cx} 43$, we postulated that $\mathrm{Cx} 43$ could recruit these enzymes to achieve the inactivation of c-Src. To test this hypothesis, glioma cells were transfected with HA-PTEN or the empty vector (pSG5L). After $24 \mathrm{~h}, \mathrm{HA}$ was immunoprecipitated (Figure 3A). Our results showed that the antibody against HA precipitated HA-PTEN, Cx43, c-Src and Csk in glioma cells transfected with $\mathrm{Cx} 43$ but not in glioma cells that lacked $\mathrm{Cx} 43$ expression (C6-Ires) or in C6-Cx43 cells transfected with pSG5L, suggesting that restoring $\mathrm{Cx} 43$ to glioma cells promotes its binding to PTEN, c-Src and Csk in glioma cells.

To address whether this interaction occurs between endogenously expressed proteins, astrocytes, which naturally express high levels of $\mathrm{Cx} 43$ and PTEN, were analyzed. Thus, $\mathrm{Cx} 43$ was immunoprecipitated, and the presence of PTEN was identified in the immunocomplex of $\mathrm{Cx} 43$ (Figure 3B). Reciprocally, $\mathrm{Cx} 43$ was also found after immunoprecipitation with antibodies against Csk in astrocytes. No signals were observed after the immunoprecipitation without $\operatorname{IgG}$ (data not shown) or with non-relevant IgGs, such as a mouse monoclonal antibody against hexokinase-1 (Hx-1) or glyceraldehyde-3-phosphate dehydrogenase (GAPDH) used as negative controls.

To confirm the results of immunoprecipitation, immunofluorescence analyses were carried out for $\mathrm{Cx} 43$, PTEN and Csk in astrocytes. The distribution of these proteins (Figure 3C; Cx43 in red and PTEN or Csk in green) was analyzed using a confocal microscope. The yellow color in the overlay images confirmed certain areas of colocalization between $\mathrm{Cx} 43$ and PTEN or Csk in astrocytes (Figure 3C). This colocalization can be visualized in the Z-projection of the stack images (Figure 3C). In addition, $\mathrm{C} 6$ glioma cells were transiently transfected with Cx43, and PTEN (green) and Cx43 (red) were analyzed by immunofluorescence $48 \mathrm{~h}$ later. The confocal images showed some points of colocalization (yellow) between the two proteins in the overlay image (Figure 3D).

\section{Region of Cx43 involved in the PTEN and Csk binding}

Regarding the molecular bases underlying the $\mathrm{Cx} 43$ PTEN binding, both $\mathrm{Cx} 43$ and PTEN harbor a functional PDZ domain-binding motif (residues 380-382 in Cx43 [35] and residues 401-403 in PTEN [36]) at their C-terminal tail. Therefore, we hypothesized that $\mathrm{Cx} 43$ and PTEN could interact through a scaffolding protein containing several PDZ domains. For instance, Zonula occludens-1 (ZO-1) binds to $\mathrm{Cx} 43$ through one of its three PDZ domains [35]; therefore, although a direct interaction between ZO-1 and PTEN has not been reported, it might occur in one of the remaining PDZ domains in ZO-1. To test this concept, C6$\mathrm{Cx} 43$ glioma cells or astrocytes were transfected with a mutant PTEN that lacks the PDZ domain-binding motif (residues 1-400; Flag $\triangle$ PDZ-PTEN), wild-type PTEN (Flag WT-PTEN) or the empty vector (Flag) (Figure 4). Flag immunoprecipitation revealed that the mutant PTEN retains the ability to bind to $\mathrm{Cx} 43$ and c-Src in glioma cells (Figure 4A) and to $\mathrm{Cx} 43$, c-Src and Csk in astrocytes (Figure 4B), indicating that the PDZ domain-binding motif is not required for these interactions.

Our previous results suggested that cell-penetrating peptides (CPPs) containing Cx43 residues involved in the c-Src interaction (residues 245-283 and 266-283 but not 274-283 in the C-terminal domain of $\mathrm{Cx} 43$ (Cx43CT)) inhibit the activity of c-Src [11]. Therefore, we investigated whether these peptides could recruit the machinery required to inhibit c-Src activity. To address this point, C6 glioma cells were incubated with biotinylated CPPs containing the SH3 domain binding motif and tyrosines phosphorylated by c-Src (from amino acid 245 to 283), the same sequence excluding the tyrosines (from amino acid 266 to 283) or a consensus SH3 domain binding motif (from amino acid 274 to 283) (Figure 5A). These peptides were all fused to the TAT penetrating sequence (YGRKKRRQRRR). After 30 minutes, pull-down assays were performed, the biotinylated peptides were recovered and proteins bound to them were analyzed (Figure 5B). Our results showed that as expected [37], c-Src was found in complex with TAT-Cx43-266-283-B, TAT-Cx43-245283-B and, to a lesser extent, TAT-Cx43-274-283-B. Interestingly, PTEN and Csk were mainly bound to TATCx43-266-283-B and, to a lesser extent, TAT-Cx43-245283-B, suggesting that this region of Cx43 (266-283) recruits not only c-Src but also PTEN and Csk. These proteins were not found when the cells were incubated with TAT-B, confirming that the sequence of $\mathrm{Cx} 43$ containing the residues 266-283 is sufficient to recruit c-Src, PTEN and Csk. The cellular internalization of these peptides was confirmed by fluorescence microscopy (Figure 5C). 

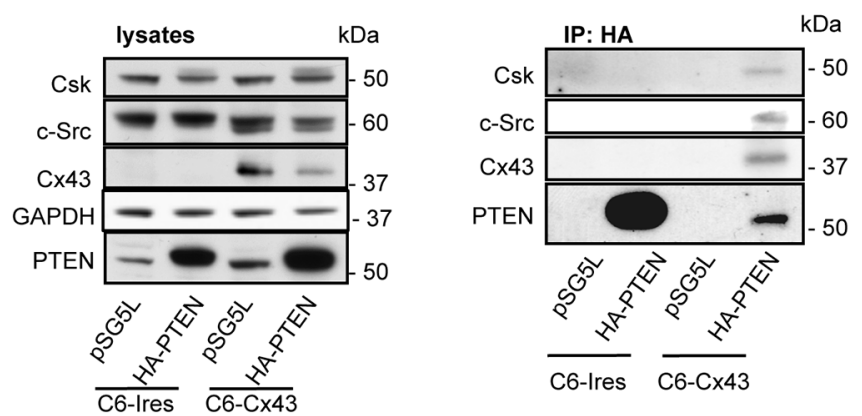

B

\section{astrocytes}
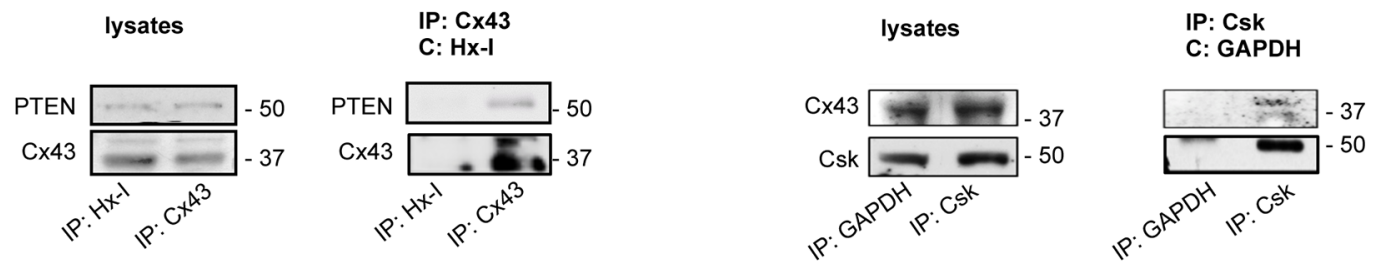

\section{C astrocytes}
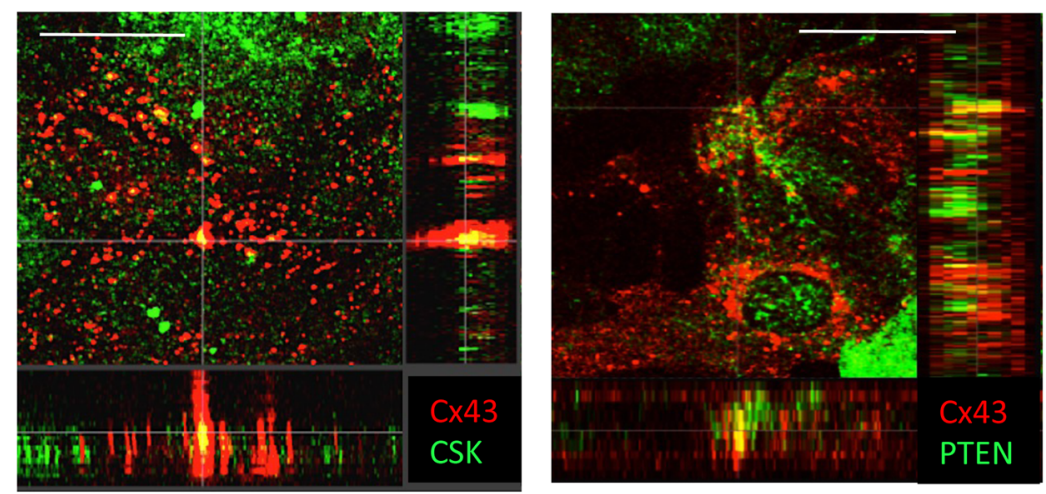

\section{D glioma cells}
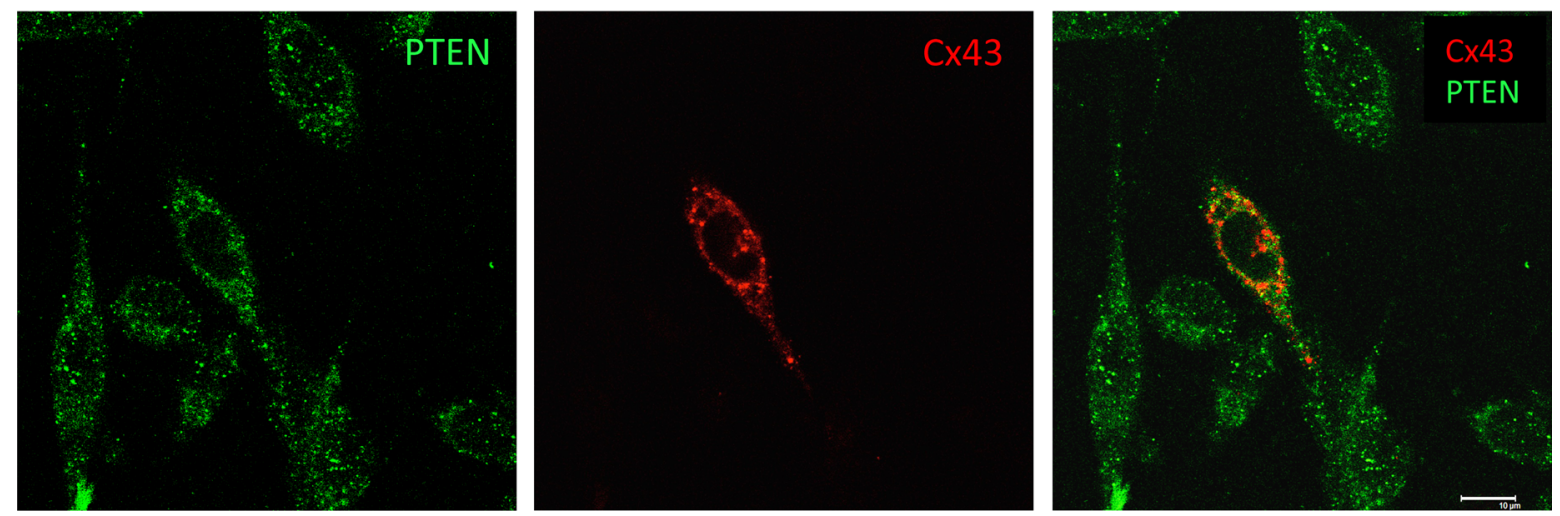

Figure 3: Interaction between Cx43, c-Src, Csk and PTEN in C6 glioma cells and astrocytes. (A) C6 glioma cells stably transfected with the empty vector (C6-Ires) or the vector containing the Cx43 cDNA(C6-Cx43) were transfected with HA-PTEN or pSG5L (empty vector). After $24 \mathrm{~h}$, the cells were lysed and immunoprecipitated with anti-HA antibodies. Western blotting before (lysates) and after HA immunoprecipitation for PTEN, Cx43, c-Src and Csk showing the presence of Csk, c-Src and Cx43 in the immunocomplex obtained with HA-PTEN in glioma cells expressing Cx43. (B) Astrocytes from primary culture were lysed and immunoprecipitated with antibodies against $\mathrm{Cx} 43$ or Csk. Antibodies against hexokinase-1 (Hx-1) and GAPDH were used as controls. (C) Colocalization of Cx43 with Csk and PTEN in astrocytes. Confocal images show Cx43 (red) and Csk or PTEN (green) and their colocalization (yellow). Scale bars: $15 \mu \mathrm{m}$. Orthogonal projections along the z-axis of the images are shown at the bottom and right. (D) Colocalization of PTEN and Cx43 in C6 glioma cells transiently transfected with the construct containing Cx43 cDNA. The confocal images show PTEN (green), Cx43 (red) and overlay image with some points of colocalization (yellow). Note that only one Cx43-transfected cell is shown. Scale bar: $10 \mu \mathrm{m}$. 


\section{TAT-Cx43-266-283 inhibits human glioblastoma stem cell growth in a PTEN-dependent fashion}

To confirm that the recruitment of PTEN and Csk to the sequence of $\mathrm{Cx} 43$ containing residues $266-283$ is sufficient to inhibit c-Src and its downstream pathway, we tested the effect of the peptide TAT-Cx43-266-283 on G166 human glioblastoma stem cells (GSCs) [38].

Our results showed that TAT-Cx43-266-283 reduced c-Src activity as evidenced by decreased levels of Y416 c-Src, increased PTEN protein levels and subsequently reduced Akt activity (T308 Akt) (Figure 6A).

As a consequence of the inhibition of these proliferative pathways, TAT-Cx43-266-283 reduced GSC proliferation compared with the control or TAT peptides (Figure 6B-6D and Supplementary Figure S1). Interestingly, when PTEN was knocked-down by siRNA (Figure 6E), TAT-Cx43-266-283 was not able to significantly affect GSC growth. This result was in contrast to the observations made in GSCs transfected with a NTsiRNA (Figure 6F) and confirms the participation of PTEN in the inhibition of c-Src that is promoted by the sequence of $\mathrm{Cx} 43$ containing the residues 266-283.

\section{DISCUSSION}

High-grade glioma cells exhibit reduced levels of Cx43 protein [3-9] but increased c-Src activity [20]. Importantly, restoring $\mathrm{Cx} 43$ expression inhibits the activity of c-Src [11, 19], reduces glioma cell proliferation [39, 40]

\section{A C6-Cx43 glioma cells}
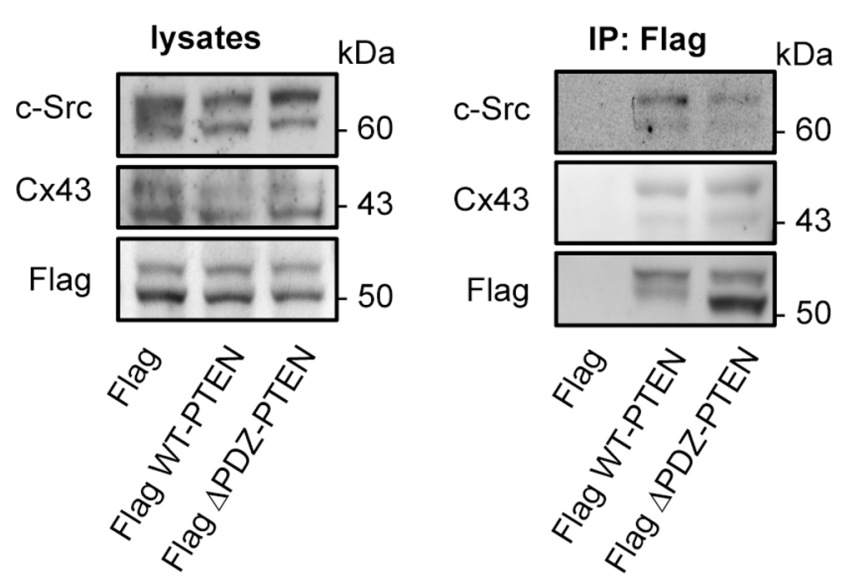

and reverses glioma stem cell phenotype [11, 12]. In this study, we revealed the mechanism by which Cx 43 inhibits the oncogenic activity of c-Src. Our results showed that $\mathrm{Cx} 43$, in addition to c-Src, recruits Csk and PTEN, which are the enzymes required to inhibit c-Src activity.

The Csk-mediated phosphorylation of $\mathrm{c}-\mathrm{Src}$ at tyrosine 527 is the best-described mechanism for c-Src inactivation [41]. The completion of this inhibition requires the dephosphorylation of c-Src at tyrosine 416 [42]. Our results suggest that in C6 glioma cells, as in other cell types [28, 43], PTEN is the phosphatase that catalyzes this process. Indeed, silencing PTEN prevented the reduction of $\mathrm{Y} 416 \mathrm{c}-\mathrm{Src}$ that was promoted by $\mathrm{Cx} 43$ in glioma cells. In addition, when either Csk or PTEN was silenced and c-Src activity could not be inhibited, the antiproliferative effect of $\mathrm{Cx} 43$ on glioma cells was reduced. It can be concluded that Csk and PTEN participate in the antiproliferative effect of $\mathrm{Cx} 43$ by inhibiting c-Src.

Intriguingly, our results showed that restoring $\mathrm{Cx} 43$ expression in glioma cells up-regulates the levels of functionally active PTEN protein. Indeed, PI3K/Akt, the main PTEN downstream pathway, is subsequently inhibited. Because the mutant $\mathrm{Cx} 43$ that lacks the ability to inhibit c-Src activity [19] did not modify PTEN levels or activity, it could be proposed that the effect of $\mathrm{Cx} 43$ on PTEN levels is a consequence of c-Src inhibition. In agreement with this proposal, the activity of c-Src promotes PTEN degradation and the subsequent activation of the PI3K/Akt pathway [33]. By showing that Cx43 up-regulates PTEN, one of the

\section{B astrocytes}

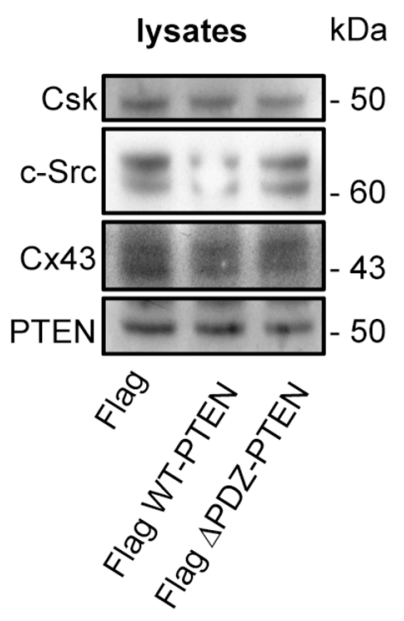

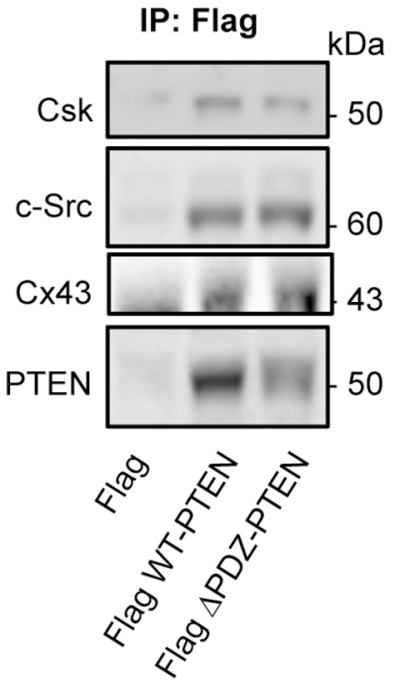

Figure 4: PTEN PDZ domain-binding motif is not required for PTEN interaction with Cx43, c-Src, and Csk. C6-Cx43 cells (A) or astrocytes (B) were transfected with Flag WT-PTEN, Flag $\triangle$ PDZ-PTEN (1-400; PTEN lacking the PDZ domain-binding motif) or Flag (control). After $48 \mathrm{~h}$, the cells were lysed, and immunoprecipitations were carried out with antibodies against Flag. Western blotting before (lysates) and after Flag immunoprecipitation for Flag, Cx43, c-Src, PTEN and Csk showing the presence of c-Src and Cx43 in the immunocomplex obtained with both WT-PTEN and $\triangle$ PDZ-PTEN in glioma cells expressing Cx43 and the presence of c-Src, Csk and Cx43 in the immunocomplex obtained with both WT-PTEN and $\triangle$ PDZ-PTEN in astrocytes that endogenously express Cx43. 
A

TAT- DPYHATSGALSPAKDCGSQKYAYFNGCSSPTAPLSPMSP

-Biotin

Cx43-274-283

Cx43-266-283

Cx43-245-283

B

\section{lysates}
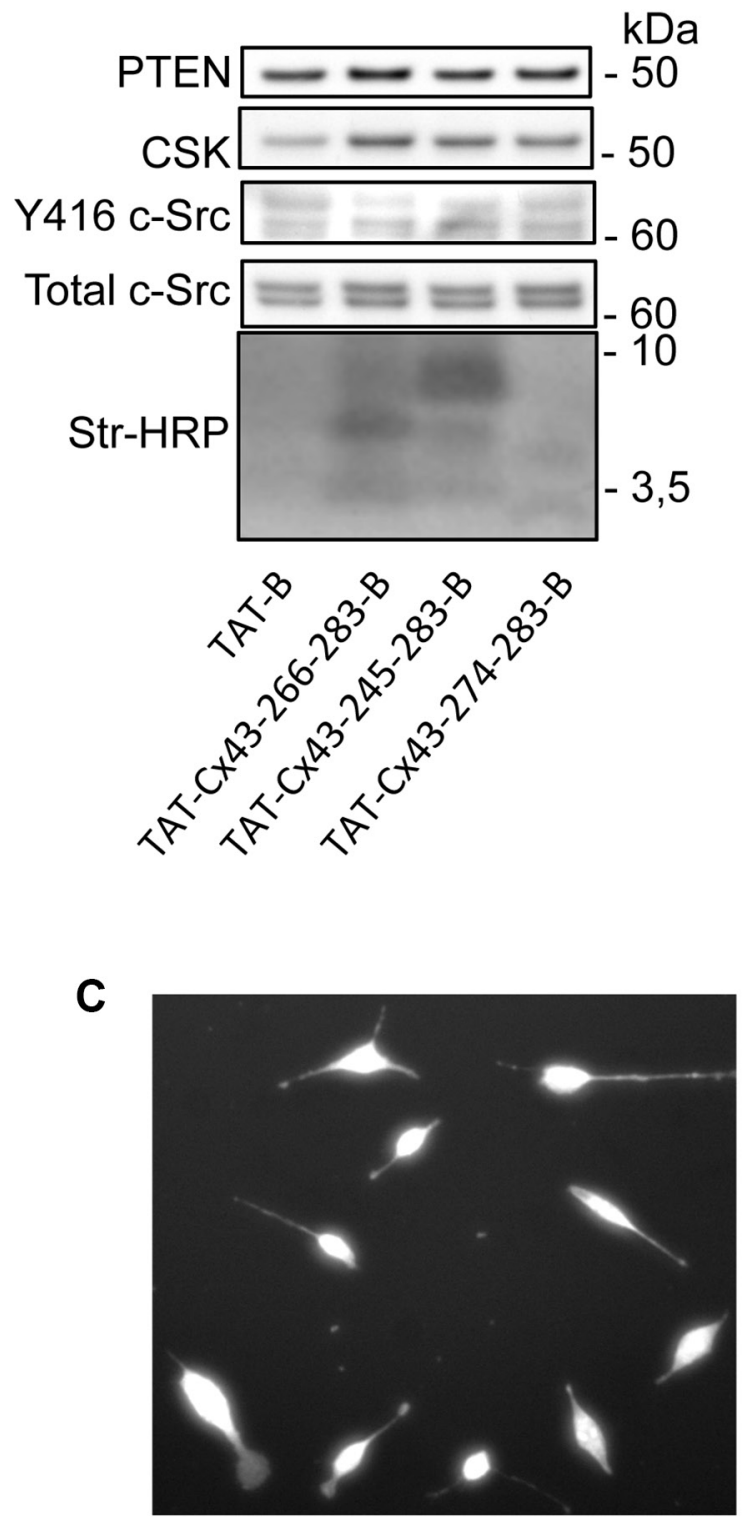

TAT-B

\section{Pull-down: Avidin}
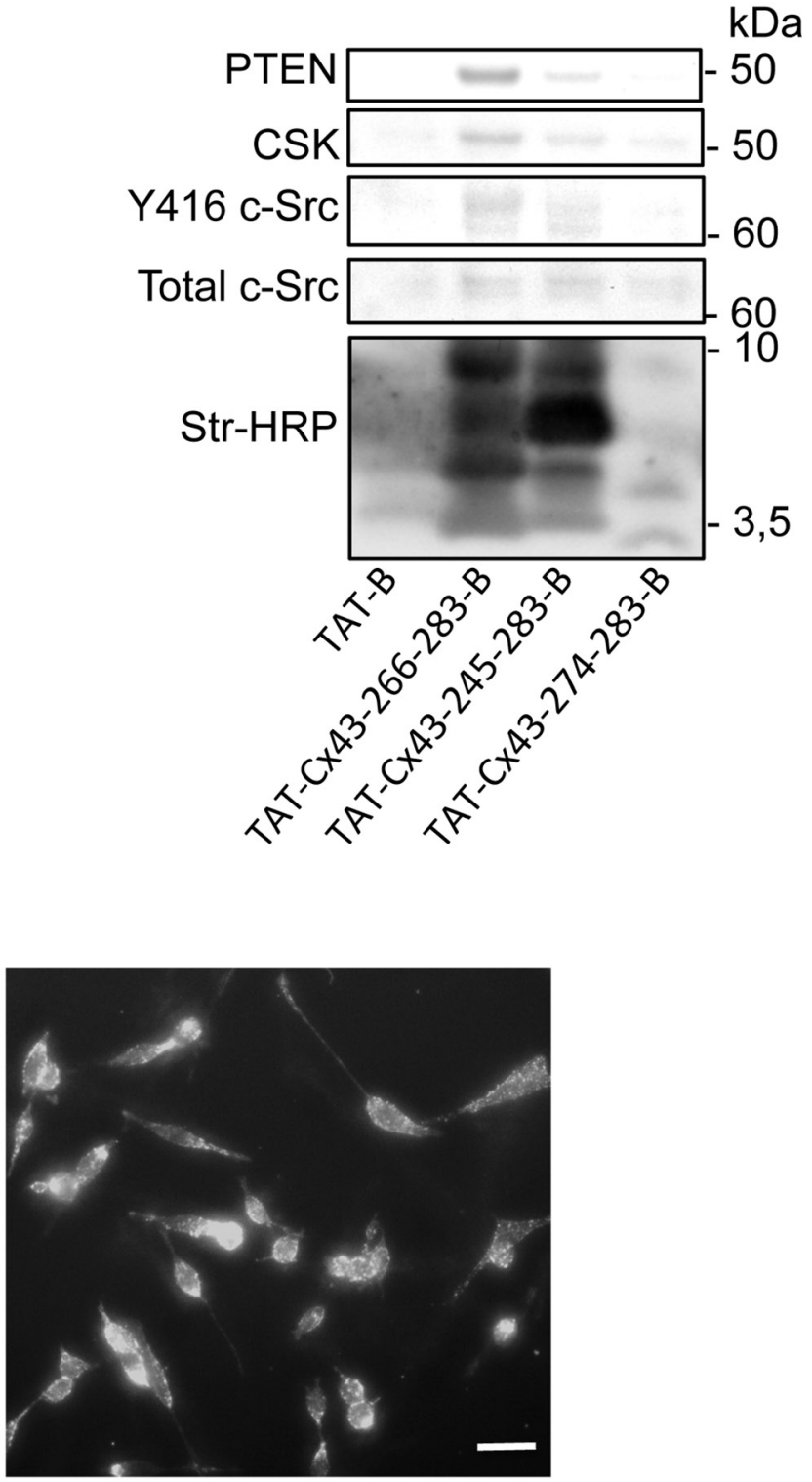

TAT-Cx43-266-283-B

Figure 5: The Cx43 region involved in the recruitment of PTEN and Csk. C6 glioma cells were incubated with several cellpenetrating peptides containing the indicated sequences of $\mathrm{Cx} 43$ fused to biotin for $30 \mathrm{~min}$. (A) The SH3 domain binding motif is shown in grey and the tyrosines phosphorylated by c-Src in red. (B) After $30 \mathrm{~min}$, the cells were lysed, and pull-down assays were carried out with avidin-conjugated agarose beads. Western blots before (lysates) and after avidin pull-down for c-Src, Csk and PTEN showing the enrichment of PTEN and Csk in the complex obtained with TAT-Cx43-266-283-Biotin and, to a lesser extent, with TAT-Cx43-245-283Biotin. Str-HRP, HRP-conjugated streptavidin. (C) After $30 \mathrm{~min}$, the cells were fixed, and the uptake of peptides bound to biotin was analyzed by fluorescence microscopy. Scale bars: $15 \mu \mathrm{m}$. 
A

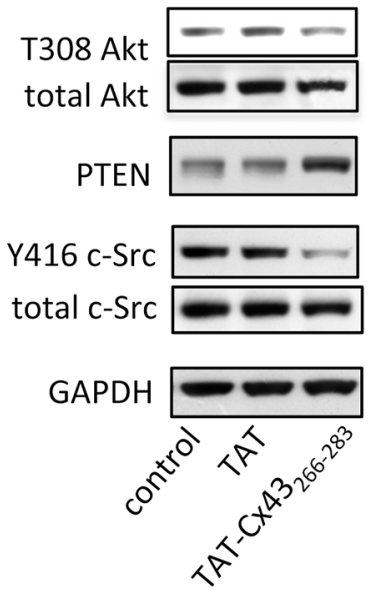

C

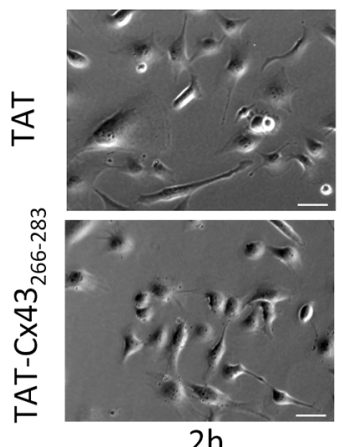

$2 \mathrm{~h}$

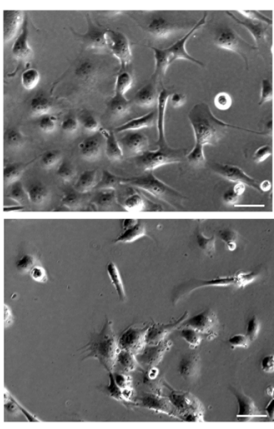

$24 \mathrm{~h}$
B

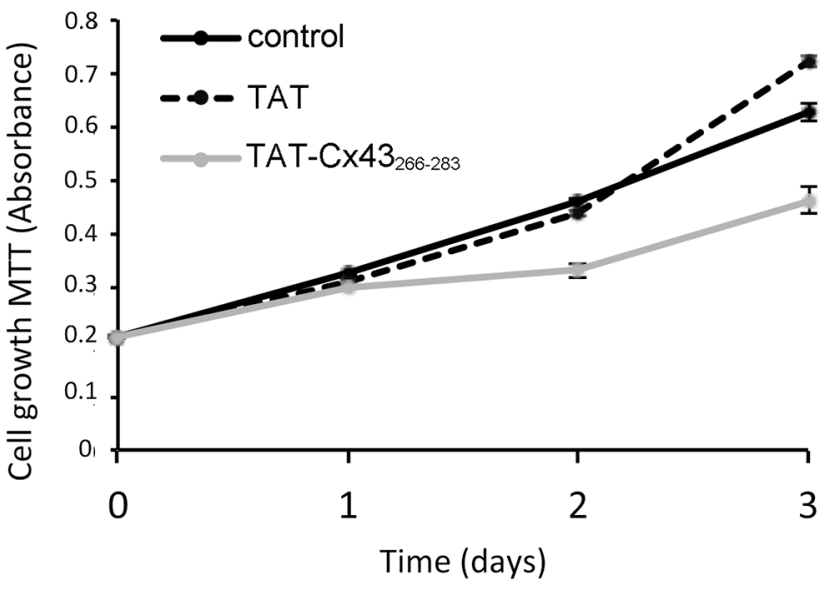

D
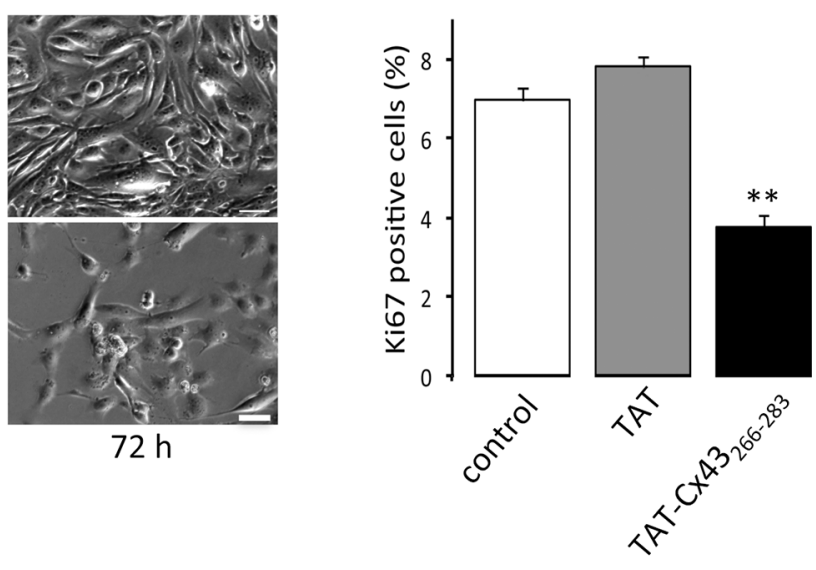

E
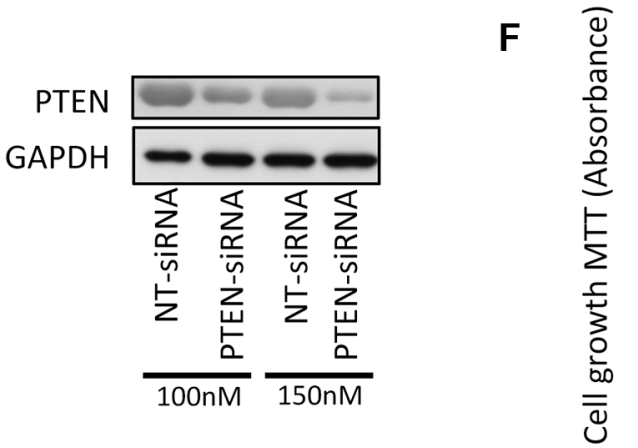

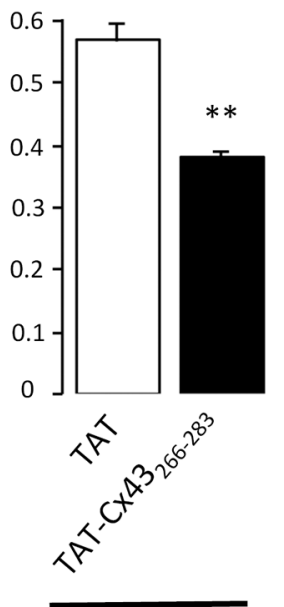

NT-siRNA

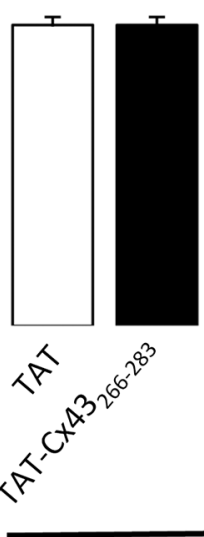

PTEN-siRNA

Figure 6: Involvement of PTEN in the antiproliferative effect of TAT-Cx43-266-283 on G166 human glioblastoma stem cells. G166 cells were incubated with $50 \mu \mathrm{M}$ TAT or TAT-Cx43-266-283 for the indicated times. (A) After $48 \mathrm{~h}$, total c-Src, Y416 c-Src, PTEN, total Akt and T308 Akt levels were analyzed by Western blotting. (B) The cells were plated at a density of $5000 \mathrm{cells} / \mathrm{cm}^{2}$ and the number of living cells was monitored over a 3 day period by the MTT assay. Means \pm s.e.m. $(n=3)$. (C) Representative phase-contrast images showing the inhibition of proliferation promoted by TAT-Cx43-266-283. Scale bars: $50 \mu \mathrm{m}$. (D) Percentage of Ki-67-positive cells found after $48 \mathrm{~h}$. Means \pm s.e.m $(n=3)$. $* * p<0.01$ versus control. (E) G166 cells were plated at 7500 cells $/ \mathrm{cm}^{2}$ and transfected with PTEN-siRNA or non-targeting siRNA (NT-siRNA). After $48 \mathrm{~h}$, PTEN levels were analyzed by Western blotting. (F) G166 cells were plated at $7500 \mathrm{cell} / \mathrm{s} / \mathrm{cm}^{2}$ and transfected with $150 \mathrm{nM}$ NT-siRNA or PTEN-siRNA. After $24 \mathrm{~h}$, the cells were incubated with $50 \mu \mathrm{M}$ TAT or TAT-Cx43-266-283 for $48 \mathrm{~h}$ and the number of living cells was analyzed by the MTT assay. Means \pm s.e.m. $(n=3)$. ${ }^{* *} p<0.01$ versus TAT NT-siRNA. 
most relevant tumor suppressor genes in gliomas [44, 45], and inhibits PI3K/Akt, an important proliferative pathway that is frequently up-regulated in glioma [46], these results expand our knowledge of the mechanism by which $\mathrm{Cx} 43$ suppresses tumor growth (Figure 7).

This study shows that in astrocytes, that express high levels of endogenous $\mathrm{Cx} 43$, there is also an interaction between $\mathrm{Cx} 43$, c-Src, Csk and PTEN, indicating that the regulation of c-Src activity is a physiological function of Cx43. c-Src phosphorylates tyrosines 265 and 247 [14], which strongly affects Cx43 structure and function [26, 37] and the interaction of $\mathrm{Cx} 43$ with several partners [47-49]. To terminate these effects, the phosphatase TC-PTP is recruited to remove the phosphates at tyrosines 265 and 247 of Cx43 [50]. However, if c-Src remained active, it would continue to phosphorylate $\mathrm{Cx} 43$. Our results suggest that $\mathrm{Cx} 43$ phosphorylation by c-Src could also be a signal to recruit PTEN and Csk to this complex. The inhibition of c-Src activity promoted by PTEN and Csk would collaborate with TC-PTP to terminate this pathway, which is required to recycle $\mathrm{Cx} 43$ [51]. In this way, the transient and dynamic interactions of these proteins would contribute to the maintenance of the homeostasis of the gap junction channel and hemichannel activities.

Although both PTEN and Cx43 contain PDZbinding motifs, our results indicated that these regions

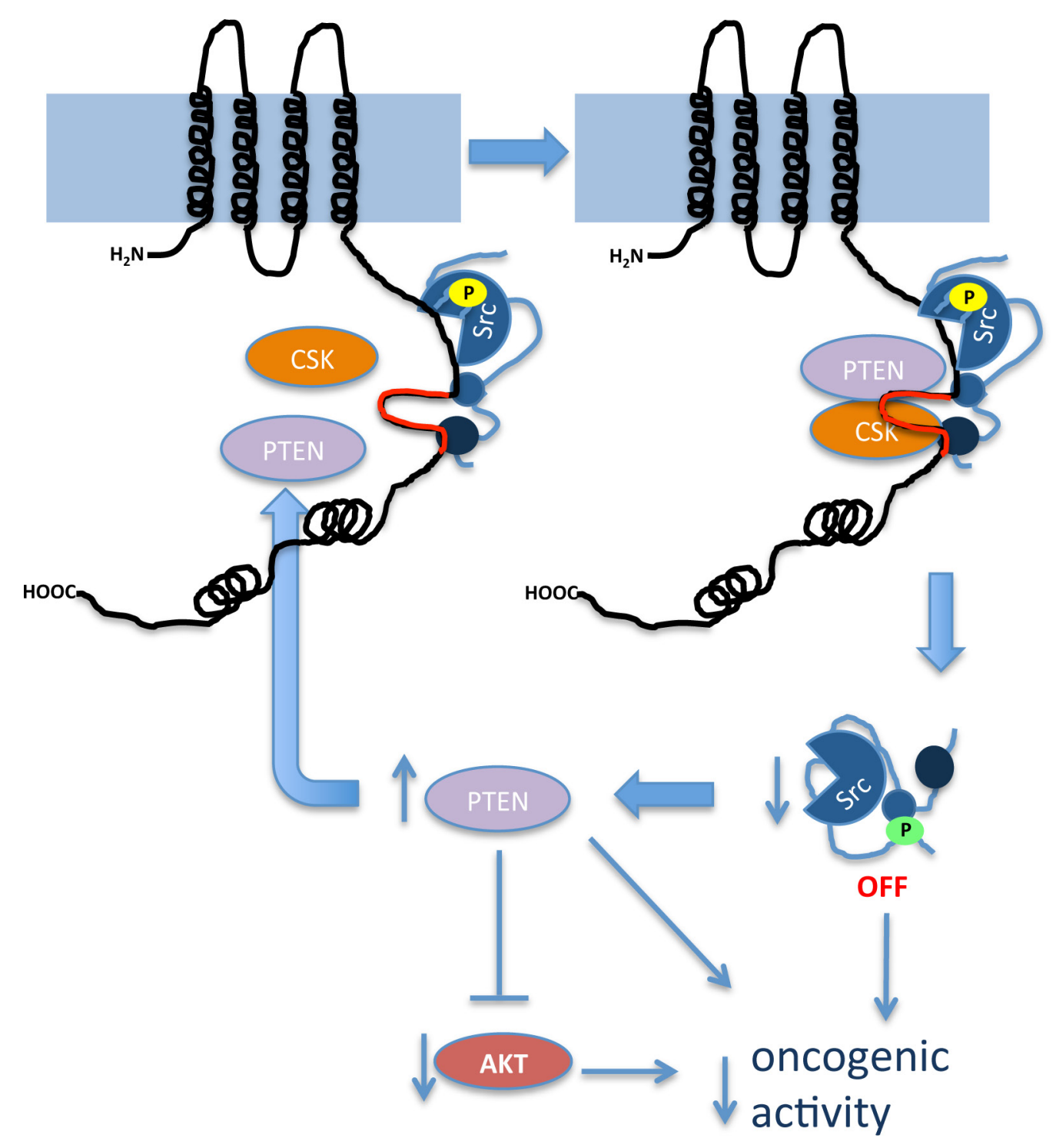

Figure 7: Proposed mechanism by which Cx43 inhibits the activity of c-Src. Our results showed that the region of Cx43 that comprises amino acids 266-283 (in red), located in one of the intrinsically disordered regions of Cx43CT, serves as a docking platform for the active form of c-Src (c-Src phosphorylated at tyrosine 416, shown in yellow), Csk and PTEN. The proximity of these proteins facilitates the phosphorylation of c-Src at tyrosine 527 (green) catalyzed by Csk and the removal of phosphate at tyrosine 416 (yellow) catalyzed by PTEN with the subsequent inhibition of c-Src activity. c-Src inhibition prevents PTEN degradation creating a positive feed-forward loop to guarantee the long-term regulation of this process. As a consequence of increased PTEN, Akt activity decreases. This signaling pathway contributes to a reduction in the oncogenic activity of these proteins in glioma cells. 
are not required for the interaction between these proteins. Instead, the region of $\mathrm{Cx} 43$ that is involved in its interaction with c-Src (residues 266-283) is sufficient to recruit PTEN and Csk. In agreement with this finding, CPPs containing this sequence (TAT-Cx43-266-283) inhibited the oncogenic activity of c-Src [11], increased PTEN, reduced Akt activity and subsequently decreased human glioblastoma stem cell proliferation.

Since it was first described, the relationship between $\mathrm{Cx} 43$ and cancer has been deeply investigated [52]. However, it should be noted that although restoring Cx43 expression in glioma cells reduces proliferation, it can also have detrimental effects due to gap junctional communication or cytoskeletal interactions [53-56]. There is interest in the short sequence (residues 266-283) of Cx43 because it inhibits the oncogenic activity of c-Src and lacks the ability to interact with the cytoskeleton or to form gap junction channels. Nevertheless, unexpected effects cannot be ruled out. Therefore, further studies should be carried out to explore the therapeutic potential of this sequence in depth.

In conclusion, we propose that the $\mathrm{Cx} 43$-mediated inhibition of c-Src involves the recruitment of the c-Src inhibitors Csk and PTEN to residues 266-283 within Cx43CT. Furthermore, upon c-Src inhibition, Cx43 upregulates PTEN and subsequently inactivates Akt to sustain its tumor suppressor properties (Figure 7). These results stress the relevance of $\mathrm{Cx} 43$ residues 266-283 for the development of new therapies to reduce the oncogenic activity of c-Src. In contrast to the available c-Src inhibitors, this approach uses an endogenous inhibitory mechanism, making off-target effects less likely.

\section{MATERIALS AND METHODS}

\section{Cell cultures}

Astrocytes in primary culture were prepared from the forebrains of 1- to 2-day-old Wistar rats and cultured in DMEM (Sigma-Aldrich Química, Madrid, Spain) supplemented with 10\% FCS (Gibco, Life Technologies, Madrid, Spain), as previously described [57]. C6 glioma cells (ATCC, Manassas, USA) were cultured in DMEM supplemented with 10\% FCS as previously described [19]. The G166 human GSC line was obtained from BioRep (Milan, Italy). The cells were grown in petri dishes coated with $10 \mathrm{mg} / \mathrm{ml}$ laminin (Life Technologies). The growth medium was RHB-A (StemCells, Cambridge, UK) supplemented with 1\% N2, 2\% B27 (Life Technologies), $20 \mathrm{ng} / \mathrm{ml} \mathrm{EGF}$ and $20 \mathrm{ng} / \mathrm{ml}$ b-FGF (PeproTech, London, UK) as described previously [11].

\section{Plasmid constructs and cell transfection}

The pIRES-Cx43 construct was generated as previously reported [19] by ligating a PCR-amplified fragment encoding the rat Cx43 sequence (NM_012567) into the XhoI-BamHI sites of the bicistronic pIRES2DsRed2 vector (Clontech, Palo Alto, CA, USA). The $\mathrm{Cx} 43 \mathrm{Y} 247 \mathrm{~F} / \mathrm{Y} 265 \mathrm{~F}$ mutation was introduced into pIRESCx43 by site-directed mutagenesis [19]. C6-Ires, C6-Cx43 and C6-Cx43 Y247F/Y265F clones were generated and characterized as previously described [19]. Unless otherwise specified, the C6 glioma cells were stably transfected with the empty vector (C6-Ires), the construct containing Cx43 (C6-Cx43) or the construct containing the mutant $\mathrm{Cx} 43$ (C6-Cx43Y247F/Y265F) using Lipofectamine 2000 (Life Technologies). For stable transfection cells were selected with $0.5 \mathrm{mg} / \mathrm{ml} \mathrm{G} 418$ (Promega, Madison, WI, USA) in DMEM supplemented with 10\% (v/v) FCS.

The pSG5L, pSG5L HA-PTEN, pCMV FLAG WTPTEN and pCMV FLAG $\triangle$ PDZ-PTEN (1-400) plasmids were a gift from William Sellers and Hong Wu and were obtained from Addgene (Addgene plasmid 10737, 10750, 22231 and 22232, respectively) [58, 59]. Cells were transiently transfected using Lipofectamine 2000, as described above.

\section{Transfection of siRNA}

C6-Cx43 clone 7 cells were transfected with a validated non-targeting siRNA (NT-siRNA), a siRNA specific for Csk (Csk-siRNA) or a siRNA specific for PTEN (PTEN-siRNA) (BioNova Científica S.L., Madrid, Spain). Cells were transfected with the doublestrand siRNA complexed with $3 \mu \mathrm{l} / \mathrm{ml}$ Lipofectamine 2000 (Life Technologies) in culture medium without antibiotics. The cells were maintained in the presence of the oligonucleotides in culture medium without antibiotics for $6 \mathrm{~h}$. The extent of siRNA-mediated down-regulation of Csk or PTEN expression was evaluated by Western blot analysis. The Csk-siRNA sequences were as follows: sense 5'-AGUACCCAGCAAAUGGGCATT-3' and antisense 5'-UGCCCAUUUGCUGGGUACUTT-3' [29]. The PTEN-siRNA sequences were as follows: sense 5'-GUUAGCAGAAACAAAAGGAGATT-3' and antisense 5'-UCUCCUUUUGUUUCUGCUAACTT-3' [30].

\section{Peptide treatments}

The synthetic peptides ( $>90 \%$ pure) were obtained from GenScript (Piscataway, NJ, USA). All peptides used were biotinylated via a C-terminal lysine. YGRKKRRQRRR-Lys(biotin) was used as the TAT sequence (TAT-B), which is responsible for cell penetration of the peptides [60]. The sequence for TATCx43-245-283-B was YGRKKRRQRRRDPYHATSGAL SPAKDCGSQKYAYFNGCSSPTAPLSPMSP-Lys(biotin), the sequence for TAT-Cx43-266-283-B was YGRKKRRQ RRRAYFNGCSSPTAPLSPMSP-Lys(biotin) and the sequence for TAT-274-283-B was YGRKKRRQRRR PTAPLSPMSP-Lys(biotin). Peptides were used at $50 \mu \mathrm{M}$ in culture medium at $37^{\circ} \mathrm{C}$ for the indicated times. 


\section{MTT assay}

Cells cultured at $37^{\circ} \mathrm{C}$ in 24-well-plates were incubated in the dark for 75 min with $300 \mu$ of DMEM containing $0.5 \mathrm{mg} / \mathrm{ml}$ MTT. The medium was then removed, and the cells were incubated for $10 \mathrm{~min}$ in the dark with dimethyl sulfoxide $(500 \mu \mathrm{l} /$ well $)$. Finally, the absorbance was measured at a wavelength of $570 \mathrm{~nm}$ using a microplate reader (Appliskan 2001; Thermo Electron Corporation, Waltham, MA, USA).

\section{Western blot analysis}

Western blotting was performed as previously described [11]. Briefly, equivalent amounts of proteins (20 $\mu \mathrm{g}$ per lane) were separated on NuPAGE Novex BisTris (4-12\% or 10\%) midigels (Life Technologies). Proteins were transblotted using an iBlot dry blotting system (Life Technologies). The membranes were cut into several strips to be immunoblotted with distinct antibodies, thus allowing for comparative analysis of the amount of each protein in the same sample. Membranes were then blocked for $1 \mathrm{~h}$ at room temperature in Tris-buffered saline containing $0.05 \%$ Tween 20 (TTBS) and $7 \%$ non-fat milk powder before being incubated overnight at $4{ }^{\circ} \mathrm{C}$ with the primary antibodies. The primary antibodies used were: $\mathrm{Cx} 43$ (1:250; BD Biosciences, Madrid, Spain; Ref. 610062); total c-Src (1:500; Ref. 2108); Y416 c-Src (1:250; Ref. 2101), Y527 c-Src (1:500; Ref. 2105), Csk (1:500; Ref. 4980), PTEN (1:500; Ref. 9552), total Akt (1:1000; Ref. 9272), S473 Akt (1:2000; Ref. 4060), T308 Akt (1:1000; Ref. 4056) (all from Cell Signaling, Danvers, MA, USA), GAPDH (1:6000; Ambion; Ref. AM4300) or $\alpha$-actinin (1:1000; Merck Millipore, Darmstadt, Germany; Ref. MAB1682). After extensive washing, the membranes were incubated with HRP-conjugated antibodies (Santa Cruz Biotechnology, Inc., Dallas, TX, USA; Refs. sc-2030 and sc-2005) in TTBS. The proteins were developed with a chemiluminescent substrate. Densitometry analysis of the bands was performed using the Image J program (Wayne Rasband; NIH, Bethesda, MD, USA). The amounts of GAPDH or $\alpha$-actinin recovered in each sample served as the loading control, and the values for each protein were normalized to their corresponding GAPDH or $\alpha$-actinin level.

\section{Immunofluorescence}

Immunofluorescence was performed as previously described [11]. The cells were incubated overnight at $4^{\circ} \mathrm{C}$ with primary antibodies against $\mathrm{Cx} 43$ (1:100; BD Biosciences; Ref. 610062), Csk (1:100), and PTEN (1:100) (both from Cell Signaling; Refs. 4980 and 9552). The secondary antibodies used were as follows: $\mathrm{Cy} 5$ goat anti-mouse (1:500; Jackson ImmunoResearch, Baltimore, PA, USA; Ref. 115-175-003) and Alexa Fluor 488 goat anti-rabbit (1:1000; Life Technologies, Ref. A-11029). The cells were mounted using the SlowFade Gold Antifade kit
(Life Technologies) and were analyzed using a Leica DMIRE2 confocal microscope and LCS Lite software (Leica Microsystems, Wetzlar, Germany).

\section{Co-immunoprecipitation}

Twenty-one DIV astrocytes or C6 cells grown to confluence in $10-\mathrm{cm}$ dishes were washed with ice-cold PBS and lysed at $4^{\circ} \mathrm{C}$ in $1 \mathrm{ml}$ of SDS-free RIPA buffer (10 mM Tris- $\mathrm{HCl}(\mathrm{pH} 8.0), 150 \mathrm{mM} \mathrm{NaCl}, 0.2 \%$ Triton X-100, 2 mM EDTA, 2 mM EGTA, 1 mM PMSF, 1:100 (v/v) protease cocktail (Cocktail III; Calbiochem MerckMillipore, Billerica, MA, EE.UU), $1 \mathrm{mM} \mathrm{NaF}$ and 0.1 $\left.\mathrm{mM} \mathrm{Na} \mathrm{VO}_{4}\right)$. Lysates were centrifuged at $11000 \times \mathrm{g}$ for $10 \mathrm{~min}$ at $4^{\circ} \mathrm{C}$, and the supernatants were recovered. A $25-\mu 1$ aliquot was used to analyze the protein content (lysates), and the remaining lysate (immunoprecipitation) was incubated with $2 \mu \mathrm{g}$ of mouse monoclonal antibody against hexokinase I (Merck Millipore; Ref. MAB1532), mouse monoclonal antibody against HA (Roche, Basel, Switzerland Ref.11 583816 001), mouse monoclonal antibody against Cx43 (BD Biosciences; Ref. 610062), rabbit monoclonal antibody against Csk (Cell Signaling; Ref. 4980) or rabbit monoclonal antibody against GAPDH (Ambion; Ref. AM4300) for $12 \mathrm{~h}$ at $4^{\circ} \mathrm{C}$ with gentle shaking. The immunocomplexes were sequestered by adding $50 \mu \mathrm{l}$ of Protein-A Sepharose CL-4B (GE Healthcare, Madrid, Spain), which was previously saturated with $5 \%(\mathrm{w} / \mathrm{v})$ albumin and gently shaken at $4^{\circ} \mathrm{C}$ for $4 \mathrm{~h}$. The Protein-A beads containing the immunocomplexes were collected by centrifugation $(11000 \times g$ for $1 \mathrm{~min}$ at $\left.4^{\circ} \mathrm{C}\right)$. The beads were then washed four times with buffer A (10 mM Tris-HCl (pH 8.0), $150 \mathrm{mM} \mathrm{NaCl}$, Triton X-100 and $2 \mathrm{mM}$ EDTA), once with buffer B (10 mM Tris- $\mathrm{HCl}$ (pH 8.0), $500 \mathrm{mM} \mathrm{NaCl}, 0.2 \%$ Triton X-100 and $2 \mathrm{mM}$ EDTA) and once with buffer $\mathrm{C}(10 \mathrm{mM}$ Tris- $\mathrm{HCl}(\mathrm{pH} 8.0))$. The bound proteins were eluted with SDS sample buffer at $95^{\circ} \mathrm{C}$ for $5 \mathrm{~min}$. After centrifugation, the supernatants were analyzed by Western blotting.

For Flag fusion proteins, the lysis buffer contained $20 \mathrm{mM}$ Tris- $\mathrm{HCl}$ (pH 8.0), $137 \mathrm{mM} \mathrm{NaCl}, 1 \%$ IGEPAL $(\mathrm{p} / \mathrm{v}), 1 \mathrm{mM}$ PMSF, 1:100 (v/v) protease cocktail (Cocktail III, Calbiochem), $1 \mathrm{mM} \mathrm{NaF}$ and $0.1 \mathrm{mM} \mathrm{Na}_{3} \mathrm{VO}_{4}$. The lysates were incubated with anti-Flag M2 Affinity Gel (40 $\mu \mathrm{l}$ per ml; Sigma, Saint Louis, MO, USA; Ref.F7425) for $12 \mathrm{~h}$ at $4^{\circ} \mathrm{C}$ with gentle shaking. The anti-Flag beads containing the immunocomplexes were collected by centrifugation $\left(11000 \times g\right.$ for $1 \mathrm{~min}$ at $\left.4{ }^{\circ} \mathrm{C}\right)$ and washed five times with lysis buffer, and the bound proteins were eluted and analyzed by Western blotting.

\section{Avidin pull-down assay}

Cells grown in $3.5-\mathrm{cm}$ dishes were incubated with $50 \mu \mathrm{M}$ biotinylated peptides for $30 \mathrm{~min}$. Proteins were then collected in $1 \mathrm{ml}$ of lysis buffer $(20 \mathrm{mM}$ Tris- $\mathrm{HCl}(\mathrm{pH}$ 8.0), $137 \mathrm{mM} \mathrm{NaCl}, 1 \%$ IGEPAL, $1 \mathrm{mM}$ PMSF, protease 
cocktail (1:100; Cocktail III, Calbiochem), $1 \mathrm{mM} \mathrm{NaF}$ and $\left.0.1 \mathrm{mM} \mathrm{Na}_{3} \mathrm{VO}_{4}\right)$. Lysates were centrifuged at $11000 \times \mathrm{g}$ for $10 \mathrm{~min}$ at $4^{\circ} \mathrm{C}$, and the supernatants were recovered. A $25-\mu 1$ aliquot of each lysate was used to analyze the protein content, and the remaining lysate was incubated with NeutrAvidin-Agarose (Thermo Scientific, Rockford, IL, USA; Ref. 29200) for $12 \mathrm{~h}$ at $4^{\circ} \mathrm{C}$ with gentle shaking. The avidin beads bound with the peptides were collected by centrifugation $\left(3000 \times g\right.$ for $1 \mathrm{~min}$ at $\left.4^{\circ} \mathrm{C}\right)$. The beads were then washed five times with lysis buffer, and the bound proteins were eluted and analyzed by Western blotting. To detect biotinylated peptides, the membranes were incubated with HRP-conjugated streptavidin in TTBS (1:40000, Ref. 434323, Life Technologies) and then developed with a chemiluminescent substrate.

In parallel, the cells were incubated with $50 \mu \mathrm{M}$ biotinylated peptides for $30 \mathrm{~min}$. The cells were then washed with $\mathrm{PBS}$ at $4^{\circ} \mathrm{C}$ and fixed with $4 \%$ paraformaldehyde for $20 \mathrm{~min}$. After washing, the cells were incubated with Cy2-conjugated streptavidin (1:500; Jackson ImmunoResearch, Baltimore, USA; Ref. 016220-084) for $1 \mathrm{~h}$, mounted and visualized as described previously.

\section{Statistical analyses}

The results were expressed as the means \pm s.e.m. of at least three independent experiments. Statistical analyses were carried out using Student's $t$-test when two groups were compared. For the comparison of more than one group, analysis of variance (one-way ANOVA) was used, followed by an appropriate post-test (Dunnet or Tukey). Values were considered significant with a $p$ value less than 0.05 .

\section{ACKNOWLEDGMENTS}

We are grateful for the technical assistance of $\mathrm{T}$ del Rey, and we thank Juan Carlos Arevalo for his help with the immunoprecipitations, Rafael Pulido for helping with the PTEN interactions and Addgene for supplying us with some of the plasmids used in this study (10737, 10750, 22231 and $22232[58,59])$.

\section{CONFLICTS OF INTEREST}

The authors declare no conflicts of interest.

\section{GRANT SUPPORT}

This work was supported by the Ministerio de Economía y Competitividad, Spain, FEDER BFU201127602, FEDER BFU2015-70040-R and Fundación Ramón Areces. A. González-Sánchez and M. JaraízRodríguez were recipient of a fellowship from the Junta de Castilla y León and the European Social Fund and M. Domínguez-Prieto from the Ministerio de Economía y Competitividad, Spain.

\section{REFERENCES}

1. Giaume C, Fromaget C, el Aoumari A, Cordier J, Glowinski J, Gros D. Gap junctions in cultured astrocytes: single-channel currents and characterization of channelforming protein. Neuron. 1991; 6:133-143.

2. Giaume C, Koulakoff A, Roux L, Holcman D, Rouach N. Astroglial networks: a step further in neuroglial and gliovascular interactions. Nat Rev Neurosci. 2010; 11:87-99.

3. Shinoura N, Chen L, Wani MA, Kim YG, Larson JJ, Warnick RE, Simon M, Menon AG, Bi WL, Stambrook PJ Protein and messenger RNA expression of connexin43 in astrocytomas: implications in brain tumor gene therapy. $\mathrm{J}$ Neurosurg. 1996; 84:839-845.

4. Huang R-P, Hossain M, Sehgal A, Boynton A. Reduced connexin43 expression in high-grade human brain glioma cells. J Surg Oncol. 1999; 70:21-24.

5. Soroceanu L, Manning T, Sontheimer H. Reduced expression of connexin-43 and functional gap junction coupling in human gliomas. Glia. 2001; 33:107-117.

6. Pu P, Xia Z, Yu S, Huang Q. Altered expression of Cx43 in astrocytic tumors. Clin Neurol Neurosurg. 2004; 107:49-54.

7. Sin WC, Crespin S, Mesnil M. Opposing roles of connexin43 in glioma progression. Biochim Biophys Acta. 2012; 1818:2058-2067.

8. Caltabiano R, Torrisi A, Condorelli D, Albanese V, Lanzafame S. High levels of connexin 43 mRNA in high grade astrocytomas. Study of 32 cases with in situ hybridization. Acta Histochem. 2010; 112:529-535.

9. Gielen PR, Aftab Q, Ma N, Chen VC, Hong X, Lozinsky S, Naus CC, Sin WC. Connexin43 confers Temozolomide resistance in human glioma cells by modulating the mitochondrial apoptosis pathway. Neuropharmacology. 2013; 75:539-548.

10. Dirks PB. Brain tumor stem cells: the cancer stem cell hypothesis writ large. Mol Oncol. 2010; 4:420-430.

11. Gangoso E, Thirant C, Chneiweiss H, Medina JM, Tabernero A. A cell-penetrating peptide based on the interaction between c-Src and connexin43 reverses glioma stem cell phenotype. Cell Death \& Disease. 2014; 5: e1023.

12. Yu SC, Xiao HL, Jiang XF, Wang QL, Li Y, Yang XJ, Ping YF, Duan JJ, Jiang JY, Ye XZ, Xu SL, Xin YH, Yao XH et al.Connexin 43 reverses malignant phenotypes of glioma stem cells by modulating E-cadherin. Stem Cells. 2012; 30:108-120.

13. Thomas SM, Brugge JS. Cellular functions regulated by Src family kinases. Annu Rev Cell Dev Biol. 1997; 13:513-609.

14. Kanemitsu MY, Loo LW, Simon S, Lau AF, Eckhart W. Tyrosine phosphorylation of connexin 43 by $\mathrm{v}-\mathrm{Src}$ is mediated by $\mathrm{SH} 2$ and $\mathrm{SH} 3$ domain interactions. J Biol Chem. 1997; 272:22824-22831.

15. Giepmans BN, Hengeveld T, Postma FR, Moolenaar WH. Interaction of c-Src with gap junction protein connexin-43. Role in the regulation of cell-cell communication. J Biol Chem. 2001; 276:8544-8549. 
16. Swenson KI, Piwnica-Worms H, McNamee H, Paul DL. Tyrosine phosphorylation of the gap junction protein connexin43 is required for the pp60v-src-induced inhibition of communication. Cell Regul. 1990; 1:989-1002.

17. Lin R, Warn-Cramer BJ, Kurata WE, Lau AF. v-Src phosphorylation of connexin 43 on Tyr247 and Tyr265 disrupts gap junctional communication. J Cell Biol. 2001; 154:815-827.

18. Solan JL, Lampe PD. Specific Cx43 phosphorylation events regulate gap junction turnover in vivo. FEBS Lett. 2014; 588:1423-1429.

19. Herrero-Gonzalez S, Gangoso E, Giaume C, Naus CC, Medina JM, Tabernero A. Connexin43 inhibits the oncogenic activity of c-Src in C6 glioma cells. Oncogene. 2010; 29:5712-5723.

20. Du J, Bernasconi P, Clauser KR, Mani DR, Finn SP, Beroukhim R, Burns M, Julian B, Peng XP, Hieronymus H, Maglathlin RL, Lewis TA, Liau LM et al. Bead-based profiling of tyrosine kinase phosphorylation identifies SRC as a potential target for glioblastoma therapy. Nat Biotechnol. 2009; 27:77-83.

21. Weissenberger J, Steinbach JP, Malin G, Spada S, Rulicke T, Aguzzi A. Development and malignant progression of astrocytomas in GFAP-v-src transgenic mice. Oncogene. 1997; 14:2005-2013.

22. Kmiecik TE, Shalloway D. Activation and suppression of pp60c-src transforming ability by mutation of its primary sites of tyrosine phosphorylation. Cell. 1987; 49:65-73.

23. Frame MC. Newest findings on the oldest oncogene; how activated src does it. J Cell Sci. 2004; 117:989-998.

24. Carlos Valle-Casuso J, Gonzalez-Sanchez A, Medina JM, Tabernero A. HIF-1 and c-Src Mediate Increased Glucose Uptake Induced by Endothelin-1 and Connexin43 in Astrocytes. Plos One. 2012; 7: e32448.

25. Gangoso E, Ezan P, Valle-Casuso JC, Herrero-Gonzalez S, Koulakoff A, Medina JM, Giaume C, Tabernero A. Reduced connexin43 expression correlates with c-Src activation, proliferation, and glucose uptake in reactive astrocytes after an excitotoxic insult. Glia. 2012; 60:2040-2049.

26. Tabernero A, Gangoso E, Jaraíz-Rodríguez M, Medina JM. The role of connexin43-Src interaction in astrocytomas: A molecular puzzle. Neuroscience. 2016; 323:183-194.

27. Okada M, Nada S, Yamanashi Y, Yamamoto T, Nakagawa H. CSK: a protein-tyrosine kinase involved in regulation of src family kinases. J Biol Chem. 1991; 266:24249-24252.

28. Zhang S, Huang WC, Li P, Guo H, Poh SB, Brady SW, Xiong Y, Tseng LM, Li SH, Ding Z, Sahin AA, Esteva FJ, Hortobagyi GN et al. Combating trastuzumab resistance by targeting SRC, a common node downstream of multiple resistance pathways. Nat Med. 2011; 17:461-469.

29. Baumeister U, Funke R, Ebnet K, Vorschmitt H, Koch S, Vestweber D. Association of Csk to VE-cadherin and inhibition of cell proliferation. EMBO J. 2005; 24:1686-1695.
30. Hettinger K, Vikhanskaya F, Poh MK, Lee MK, de Belle I, Zhang JT, Reddy SA, Sabapathy K. c-Jun promotes cellular survival by suppression of PTEN. Cell Death Differ. 2007; 14:218-229.

31. Research NCGA. Comprehensive genomic characterization defines human glioblastoma genes and core pathways. Nature. 2008; 455:1061-1068.

32. Sarbassov DD, Guertin DA, Ali SM, Sabatini DM. Phosphorylation and regulation of Akt/PKB by the rictormTOR complex. Science. 2005; 307:1098-1101.

33. Lu Y, Yu Q, Liu JH, Zhang J, Wang H, Koul D, McMurray JS, Fang X, Yung WK, Siminovitch KA, Mills GB. Src family protein-tyrosine kinases alter the function of PTEN to regulate phosphatidylinositol 3-kinase/ AKT cascades. J Biol Chem. 2003; 278:40057-40066.

34. Lampe PD, Lau AF. The effects of connexin phosphorylation on gap junctional communication. Int J Biochem Cell Biol. 2004; 36:1171-86.

35. Giepmans B, Moolenaar W. The gap junction protein connexin43 interacts with the second PDZ domain of the zona occludens-1 protein. Curr Biol. 1998; 8:931-934.

36. Valiente M, Andres-Pons A, Gomar B, Torres J, Gil A, Tapparel C, Antonarakis SE, Pulido R. Binding of PTEN to specific PDZ domains contributes to PTEN protein stability and phosphorylation by microtubule-associated serine/ threonine kinases. J Biol Chem. 2005; 280:28936-28943.

37. Sorgen PL, Duffy HS, Sahoo P, Coombs W, Delmar M, Spray DC. Structural changes in the carboxyl terminus of the gap junction protein connexin43 indicates signaling between binding domains for c-Src and zonula occludens- 1 . J Biol Chem. 2004; 279:54695-54701.

38. Pollard SM, Yoshikawa K, Clarke ID, Danovi D, Stricker S, Russell R, Bayani J, Head R, Lee M, Bernstein M, Squire JA, Smith A, Dirks P. Glioma stem cell lines expanded in adherent culture have tumor-specific phenotypes and are suitable for chemical and genetic screens. Cell Stem Cell. 2009; 4:568-580.

39. Zhu D, Caveney S, Kidder GM, Naus CCG. Transfection of C6 glioma-cells with connexin-43 cDNA - analysis of expression, intercellular coupling, and cell-proliferation. Proc Natl Acad Sci USA. 1991; 88:1883-1887.

40. Huang RP, Fan Y, Hossain MZ, Peng A, Zeng ZL, Boynton AL. Reversion of the neoplastic phenotype of human glioblastoma cells by connexin 43 (cx43). Cancer Res. 1998; 58:5089-5096.

41. Okada M, Nakagawa H. Identification of a novel protein tyrosine kinase that phosphorylates pp60c-src and regulates its activity in neonatal rat brain. Biochem Biophys Res Commun. 1988; 154:796-802.

42. Schwartzberg PL. The many faces of Src: multiple functions of a prototypical tyrosine kinase. Oncogene. 1998; 17:1463-1468. 
43. Dey N, Crosswell HE, De P, Parsons R, Peng Q, Su JD, Durden DL. The protein phosphatase activity of PTEN regulates SRC family kinases and controls glioma migration. Cancer Res. 2008; 68:1862-1871.

44. Li J, Yen C, Liaw D, Podsypanina K, Bose S, Wang SI, Puc J, Miliaresis C, Rodgers L, McCombie R, Bigner SH, Giovanella BC, Ittmann $\mathrm{M}$ et al. PTEN, a putative protein tyrosine phosphatase gene mutated in human brain, breast, and prostate cancer. Science. 1997; 275:1943-1947.

45. Song MS, Salmena L, Pandolfi PP. The functions and regulation of the PTEN tumour suppressor. Nat Rev Mol Cell Biol. 2012; 13:283-296.

46. Chakravarti A, Zhai G, Suzuki Y, Sarkesh S, Black PM, Muzikansky A, Loeffler JS. The prognostic significance of phosphatidylinositol 3-kinase pathway activation in human gliomas. J Clin Oncol. 2004; 22:1926-1933.

47. Bejarano E, Yuste A, Patel B, Stout RF Jr, Spray DC, Cuervo AM. Connexins modulate autophagosome biogenesis. Nat Cell Biol. 2014; 16:401-414.

48. Toyofuku T, Akamatsu Y, Zhang H, Kuzuya T, Tada M, Hori M. c-Src regulates the interaction between connexin-43 and ZO-1 in cardiac myocytes. J Biol Chem. 2001; 276:1780-1788.

49. Saidi Brikci-Nigassa A, Clement MJ, Ha-Duong T, Adjadj E, Ziani L, Pastre D, Curmi PA, Savarin P. Phosphorylation controls the interaction of the connexin43 C-terminal domain with tubulin and microtubules. Biochemistry. 2012; 51:43314342.

50. Li H, Spagnol G, Naslavsky N, Caplan S, Sorgen PL. TC-PTP directly interacts with connexin43 to regulate gap junction intercellular communication. J Cell Sci. 2014; 127:3269-3279.

51. Carette D, Gilleron J, Denizot JP, Grant K, Pointis G, Segretain D. New cellular mechanisms of gap junction degradation and recycling. Biol Cell. 2015; 107:218-231.
52. Loewenstein WR, Kanno Y. Intercellular communication and the control of tissue growth: lack of communication between cancer cells. Nature. 1966; 209:1248-1249.

53. Sin WC, Aftab Q, Bechberger JF, Leung JH, Chen $\mathrm{H}$, Naus CC. Astrocytes promote glioma invasion via the gap junction protein connexin43. Oncogene. 2016; 35:1504-1516.

54. Hong X, Sin WC, Harris AL, Naus CC. Gap junctions modulate glioma invasion by direct transfer of microRNA. Oncotarget. 2015; 6:15566-15577. doi: 10.18632/ oncotarget.3904.

55. Matsuuchi L, Naus CC. Gap junction proteins on the move: connexins, the cytoskeleton and migration. Biochim Biophys Acta. 2013; 1828:94-108.

56. Chen Q, Boire A, Jin X, Valiente M, Er EE, Lopez-Soto A, Jacob LS, Patwa R, Shah H, Xu K, Cross JR, Massagué J. Carcinoma-astrocyte gap junctions promote brain metastasis by cGAMP transfer. Nature. 2016; 533:493-498.

57. Tabernero A, Orfao A, Medina J. Astrocyte differentiation in primary culture followed by flow cytometry. Neurosci Res. 1996; 24:131-138.

58. Ramaswamy S, Nakamura N, Vazquez F, Batt DB, Perera S, Roberts TM, Sellers WR. Regulation of G1 progression by the PTEN tumor suppressor protein is linked to inhibition of the phosphatidylinositol 3-kinase/Akt pathway. Proc Natl Acad Sci U S A. 1999; 96:2110-2115.

59. Mosessian S, Avliyakulov NK, Mulholland DJ, Boontheung P, Loo JA, Wu H. Analysis of PTEN complex assembly and identification of heterogeneous nuclear ribonucleoprotein $\mathrm{C}$ as a component of the PTEN-associated Complex. J Biol Chem. 2009; 284:30159-30166.

60. Gump JM, Dowdy SF. TAT transduction: the molecular mechanism and therapeutic prospects. Trends Mol Med. 2007; 13:443-448. 